\title{
Metastatic Tuberculomas along a Nonfunctioning Ventricular Catheter
}

\author{
Laxmikant Bhople ${ }^{1}$ H Kharosekar ${ }^{1}$ Anuj Bhide ${ }^{1}$ V Velho $^{1}$ \\ ${ }^{1}$ Department of Neurosurgery, Sir J J group of Hospitals and Grant \\ Address for correspondence Hrushikesh U Kharosekar, MCh, \\ Medical College, Mumbai, Maharashtra, India \\ Department of Neurosurgery, 4th floor, Grant Medical College and \\ Sir J J Group of Hospitals, Byculla E, Mumbai, 400008, Maharashtra, \\ India (e-mail: hkharosekar@gmail.com).
}
Abstract
Keywords
- tuberculomas
- shunt tube
- ventricular catheter
- chemotherapy
A unique case of tubercular meningitis, developing shunt complication, is being reported. We present a pediatric patient with disseminated tubercular granulomas along the ventricular catheter of a nonfunctional ventriculoperitoneal shunt.

\section{Introduction}

The diagnosis of tuberculous meningitis is suspected in any case of subacute meningitis, presenting in an endemic area, with a cerebrospinal fluid analysis of predominant lymphocytes (100-500 cells $/ \mathrm{mm}^{3}$ ) and elevated protein value (100-500 mg/dL), and hypoglycorrhachia. ${ }^{1}$ Eighty percent of patients with tubercular meningitis develop hydrocephalus in which $65 \%$ of patients need cerebrospinal fluid (CSF) diversion. ${ }^{2}$ Two-third of patients belong to pediatric age group in which majority of them are males. We present a unique case of tubercular meningitis, which had dissemination of tubercular bacilli along the ventricular end of the shunt, even while on antitubercular chemotherapy.

\section{Case Report}

An 8-year-old male child presented with a history of blurring of vision and headache for the last 4 months and imbalance and giddiness for the last 4 months. Previously, patient was diagnosed as having tubercular meningitis on CSF analysis and was shunted by right parietal Ventriculoperitoneal (VP) shunt 3 years back at another institute for hydrocephalus ( - Fig. 1). Patient had received full dose of chemotherapy of isoniazid, rifampicin, streptomycin, and pyrazinamide as per weight at that time. On investigation, patient had

published online February 9, 2021
DOI https://doi.org/ 10.1055/s-0040-1714315 ISSN 2277-954X. features suggestive of shunt dysfunction and it was seen that the shunt tube was partially in the parenchyma. At surgery, this previous shunt tube could not be removed due to adhesions and a left-sided VP shunt surgery was performed. The patient improved after VP shunt with visual acuity and headache improving. After remaining asymptomatic for 1 month, patient again presented with altered sensorium. Magnetic resonance imaging brain was performed and it was seen that the patient had developed tuberculomas along the ventricular end of his right-sided VP shunt (-Fig. 2). The patient was started on second-generation antitubercular treatment and steroids and there was clinical response to the above-mentioned regimen. Patient improved symptomatically and was discharged for follow-up at 3 months.

\section{Discussion}

There is a definite pathogenetic correlation between the occurrence of tubercular meningitis and tuberculomas. On magnetic resonance imaging, tuberculomas appear hypo to isointense on T2-weighted imaging, rim-enhancing lesions on post-contrast T1-weighted imaging (-Fig. 2), and hyperintense signals on diffusion-weighted imaging. A fatal case of tubercular bacilli dissemination through ventriculoatrial shunt, causing recurrent miliary tuberculosis, has been reported earlier. A case of caseous granuloma at the

(C) 2021. Neurological Surgeons' Society of India.

This is an open access article published by Thieme under the terms of the Creative Commons Attribution-NonDerivative-NonCommercial-License, permitting copying and reproduction so long as the original work is given appropriate credit. Contents may not be used for commercial purposes, or adapted, remixed, transformed or built upon. (https://creativecommons.org/licenses/by-nc-nd/4.0/) Thieme Medical and Scientific Publishers Pvt. Ltd. A-12, 2nd Floor, Sector 2, Noida-201301 UP, India 


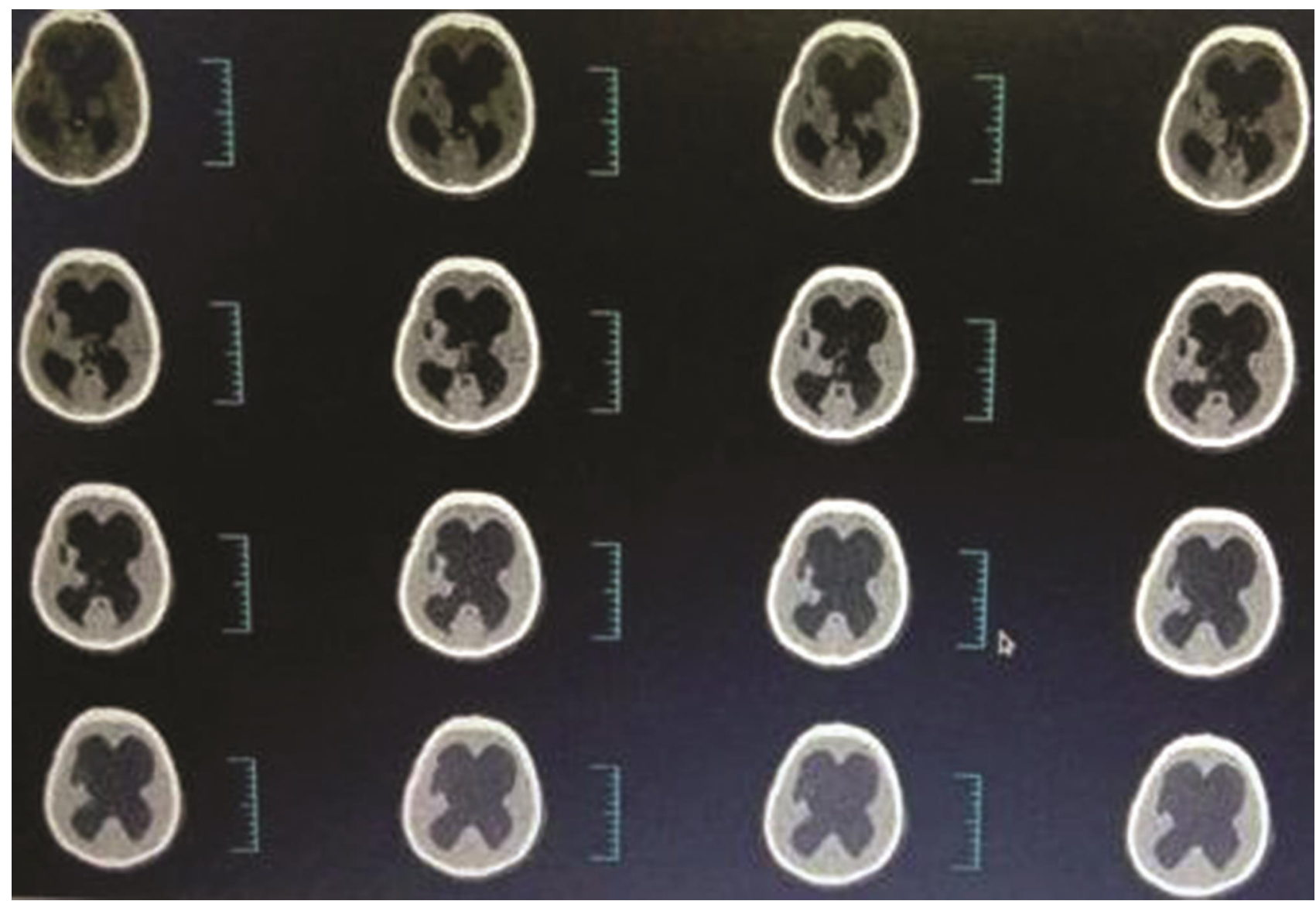

Fig. 1 Computed tomography brain showing hydrocephalus prior to ventriculoperitoneal shunt.

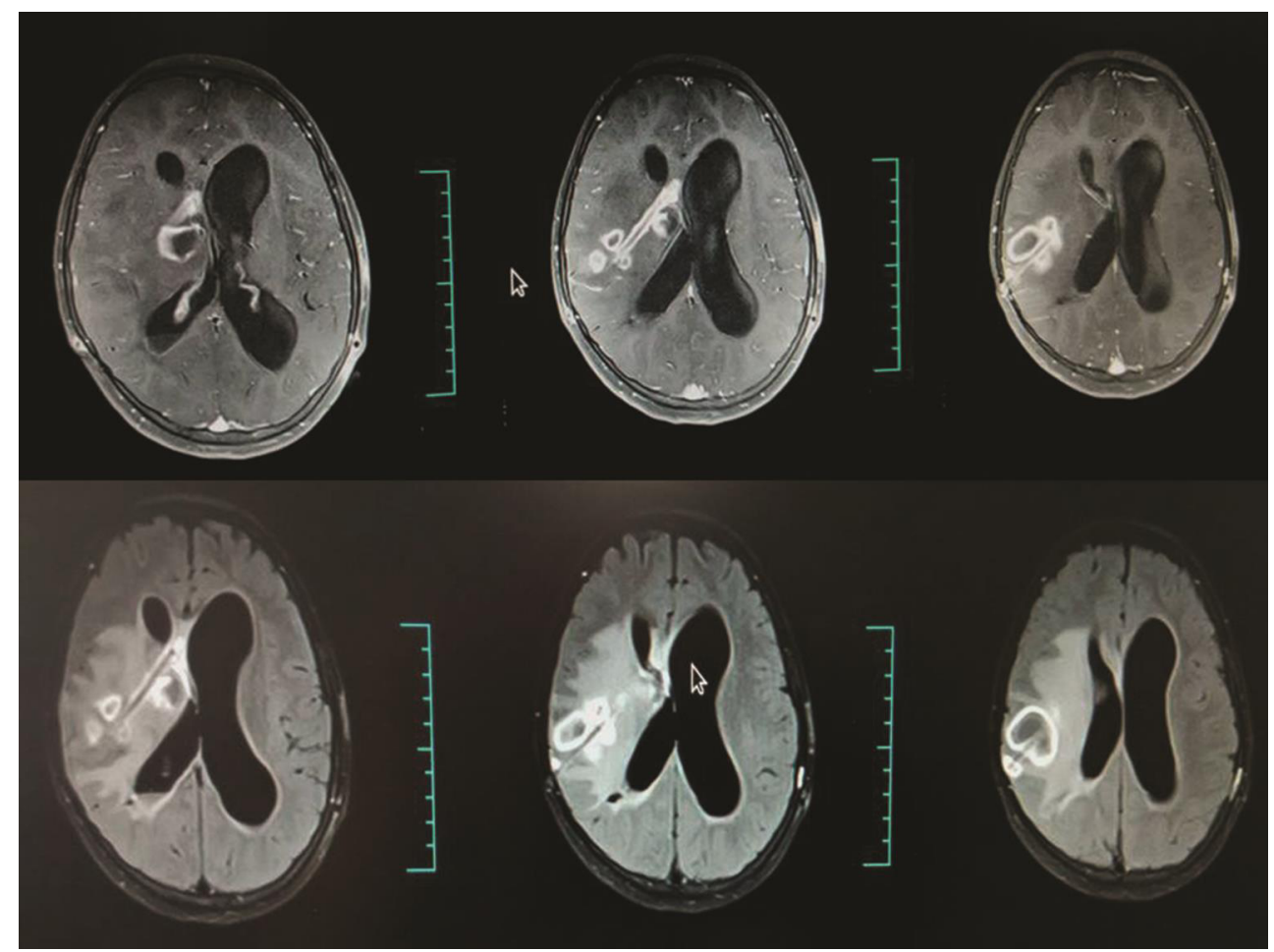

Fig. 2 Magnetic resonance imaging brain with contrast showing multiple tuberculomas along the shunt tube track. 
peritoneal end of a VP shunt has also been reported. ${ }^{3}$ Hence, the prosthesis-induced bacilli transmission and spread have been documented earlier. However, the persistence of bacilli after 1 year of chemotherapy is noteworthy. ${ }^{2}$

Our case had tubercular meningitis and dissemination intraparenchymal along a nonfunctional shunt tube is a noteworthy finding and has not been reported in literature.

\section{Conclusion}

Tubercular bacilli may persist in spite of full dose of chemotherapy. A latent period of 2 weeks may be provided, before inserting shunt, so as to minimize the chance of bacilli dissemination. Wherever possible, a nonfunctioning shunt prosthesis should be excised to avoid such an untoward complication.

\section{Conflict of Interest}

None declared.

\section{References}

1 Teil R, Rosenblum ML. Chapter 339, Chronic granulomatous lesions: tuberculosis, leprosy, sarcoidosis. In: Rengachary SS, Wilkins RH, eds. Textbook of Neurosurgery 1996. Second edition. McGraw Hill. 3341-3350

2 Mohindra S, Gupta R, Chhabra R. Dissemination of tubercular bacilli by shunt placement. Ann Neurosci 2009;16(2)10.5214/ ans.0972.7531.2009.160211

3 Shibolet S, Dan M, Jedwab M, Goldhammer Y, Baum GL. Recurrent miliary tuberculosis secondary to infected ventriculoatrial shunt. Chest 1979;76(3):328-330 